\title{
Balanced Scorecard for the Digital Transformation of Global Container Shipping Lines
}

\author{
Svetlana Maydanova \\ Unifeeder A/S branch of Unifeeder A/S \\ in St.-Petersburg, $R F$ \\ St.-Petersburg, Russia \\ sma@unifeeder.com \\ Ann-Kathrin Lange \\ Institute of Maritime Logistics \\ Hamburg University of Technology \\ Hamburg, Germany \\ ann-kathrin.lange@tuhh.de
}

\author{
Igor Ilin \\ Peter the Great Saint-Petersburg \\ Polytechnic University \\ St. Petersburg, Russia \\ ivi2475@gmail.com \\ Vadim Korablev \\ Peter the Great Saint-Petersburg \\ Polytechnic University \\ St. Petersburg, Russia \\ korablev@spbstu.ru
}

\author{
Carlos Jahn \\ Institute of Maritime Logistics \\ Hamburg University of Technology \\ Hamburg, Germany \\ Carlos.jahn@tuhh.de
}

\begin{abstract}
The liner container shipping industry is at a maturity stage. and companies undertake strategic changes to resolve key problems by using for example the digital transformation. The digital transformation is the process of digital technologies integration into all company business activities, requiring fundamental changes by introducing new technologies, cultures, operations and the new products and services creation principles.
\end{abstract}

For digital transformation success established companies need to undertake consecutive actions starting from the strategic vision and followed by fundamental realization mechanisms. There is a strong requirement of the new architectural concepts creation, allowing the companies to get a competitive advantage and to provide strategic alignment of business and IT architecture for further successful development.

In this research paper architectural approach concepts to the global container shipping line information systems are formulated, the Enterprise Strategic Alignment Method, allowing the company effective development during the global changes of forms and methods of business is adapted and the Balanced Scorecard for digital transformation control is developed.

Keywords-container shipping, Balanced Scorecard, digital transformation, value-based management

\section{INTRODUCTION}

Currently there is a new competitive environment emergence and fundamental change in traditional industries, within the concept of "Industry 4.0" companies predict horizontal and vertical processes intensive digitalization in a value creation chain. This becomes impossible without architectural approach application to the company information systems. [1]

The container liner shipping industry is at a maturity stage, which is characterized by declining income growth, structural overcapacity which has a negative impact on the markets. Besides, the companies who are established in the industry experience competition from "digital disruptors", i.e. new companies which are digital savvy. For the key problems resolving companies the established companies undertake strategic changes, such as business consolidation, processes integration, investments into digitalization. [2]
Analysts define seven trends of digital transformation, which are capable to change soon the container liner shipping industry: blockchain, electronic platforms, Internet of things, predictive analytics, artificial intelligence, autonomous vessels and robotics, and cyber security. [3]

It should be noted that digital transformation is the process of digital technologies integration into all company business activities, requiring fundamental changes by introducing new technologies, culture, operations and new products and services. The creation of new business offers for company clients and partners remains the digital transformation obligatory feature. [3]

For the digital transformation success, companies need to undertake consecutive actions starting from the strategic vision and followed by fundamental realization mechanisms. There is a strong requirement of the new architectural concepts creation, allowing the industry leaders to get a competitive advantage and to provide strategic alignment of business and IT architecture for further successful development. [3]

The aim of this research paper is to create an architectural approach concept to the global container liner shipping information systems formulation, the Enterprise Strategic Alignment Method adoption and the development of a Balanced Scorecard for a company's digital transformation control.

\section{MATERIALS AND METHODS}

Strategic alignment is a continuous process of adaptation and change in which organizations try to create synergy between their position within their competitive environment and the design of the appropriate structure to support the execution. [4]

The Enterprise Strategic Alignment Method (ESAM) represents a cross-domain approach to the company business and IT architecture alignment in order to achieve its strategic objectives. This method combines such discipline approaches as Strategic Management, Capability 
Based-Planning, Enterprise Architecture and Enterprise Portfolio Management. [5]

ESAM is presents a company activity business model as a subject domain, allowing to coordinate all strategic stages of the company transformation according to its changes.

ESAM can be applied at any stage. In this research paper the method is adapted for global container shipping lines digital transformation planning and implementation. For this purpose, in this paper there are strategic models as Business Model Canvas [6], Capability Based Planning [7-8] used. The global container shipping line is considered as a logistics system in terms of the value-based Supply Chain Management concept [9]. and developed the Balanced Scorecard [10], allowing to estimate the digital transformation impact on the company long-term shareholder value. For global container shipping line strategic map modelling there were applied International Accounting Standards (could be GAAP standards as well) IAS, strategic model Marketing Mix, Supply Chain Operations Reference Model, BIMCO Shipping KPI's standard, IMO standard, Capacity Management practice, international frameworks COBIT, ITIL, enterprise architecture modeling language Archimate and modeling tool Archi.

\section{RESULTS}

Enterprise architecture influence on the realization of a company's strategy is considered by many modern researchers. During the industry digital transformation and the new competitive environment formation, it is necessary to formulate the following architectural approach concepts to the global container shipping line information systems:

1. Digital business ecosystem architecture [11].

2. New network communications and new storage and data processing technologies development [11].

3. Strong inherent relationship between three main aspects, namely EA models, data from enterprise information systems and IoT devices, and advanced analytics [12].

The business model describes the basic principles of the company creation, development and successful activity. According to a Business Model Canvas, a company business model consists of nine blocks, which reflect the logic of the company activity and are aimed to generate profit. These nine blocks cover four main business aspects: customer relationship, value proposition, company infrastructure and financial efficiency. The business model is like a strategic plan, which is realized through organizational structures, processes and systems.[6]

We need to consider what changes will occur in the global container liner shipping liner business model during the digital transformation:

1. Key Activities: business ecosystem creation which provides for clients and partners the higher value of services in a value creation chain.
2. Value Propositions: flexibility, transportation process transparency, focus on real client demand, end-toend supply chain solution.

3. Key Partnerships: during network rivalry era, it is necessary to use effectively resources and competences of a business ecosystem partners. Yesterday's competitors become partners as well, the role of IT - the companies and digital startups increases.

4. Key Resources: IT resources from the best of possible operational needs support tool, with the least strategic impact, become the technological transformation mechanism, requirements to IT resources must be aligned with the company strategic goals.

5. Customer Relationships: IT-infrastructures change provides customer relationship new opportunities such as automated services and co-creation.

6. Channels: company e-platforms and partner eplatforms for freight and other services sale will allow excluding intermediaries from the supply chain.

7. Customer Segments: processes automation and digitalization will allow global container shipping lines to implement direct sales for cargo owners, consignees and large international shipping companies, to exclude intermediaries from the supply chain, reduce client transportation costs and improve containers delivery transparency. Besides, there will appear new customer segment - the satellite companies, creating additional value in the supply chain.

8. Cost Structure: digital transformation will allow to optimize costs for vessel calls network, empty containers relocation, fleet and containers maintenance, overhead costs, however IT and cyber security costs will increase.

9. Revenue Streams: In addition to freight and associated income, there will appear new income types based on rendered services new quality.

Thus, global container shipping lines digital transformation will affect all nine blocks of a company's business model, what can proof the imminent need of phased introduction of the latest technologies in the container shipping industry.

Strategic management researchers have investigated for the last decades how organizations can gain and maintain the competitive advantage dynamic situations. This has led to the formulation of multiple theories, with a focus on resources and capabilities as a source for a competitive advantage. Whereas resource-based theories focus on accumulating of valuable, rare, inimitable and nonsubstitutable (VRIN) resources, the capability-based theories focus on adapting, integrating and re-configuring internal and external organizational skills, recourses and functional competencies toward a changing environment. [5]

To characterize the global container liner shipping business capabilities more precisely it is necessary to consider the company as a complex logistic network, the international supply chain basis.

Thus, the logistic network represents the multilayered closed flow process: the upstream and downstream flows of products, services, finances, and information. Logistic 
networks, united by logistic agreements, represent a supply chain. [9]

Therefore, global container shipping lines digital transformation should provide effect on physical, logistical, financial and service supply chain flows.

During the company's digital transformation, it is necessary to analyze technical capabilities and their influence on the company's strategic goals achievement. For determination of new business model introduction commercial value and cost there need to be defined quality and quantitative, natural and ad valorem strategic indicators, for this purpose the value-based management theory could be used.

Value-based management (VBM) is a creation of an activity results assessment system on the company value basis and aligning management tools in accordance with this integrated indicator. Based on the comprehension of Modigliani and Miller (1958), the financial value of a firm is determined by the present value of its future cash flows. [13]

There is a direct interrelation between the company value and its business model as used business model determines company future cash flows. [9]

The concept of value-based management (VBM) is linked to the shareholder value. Shareholder value and debt are seen as complementary portions of the total economic value of a company or business unit. The maximization of shareholder value is perceived as the primary objective of a company, and hence VBM stipulates that all parts of a company are managed in such a way that the equity value of this entity is increased, i.e. shareholder value is added. Being obliged to this objective by defined targets and effective compensation packages, management can apply decision making in financing, investing and operating in order to improve the operating profit, increase the capital turnover and reduce the effective tax rate. These value drivers in turn have an impact on the valuation components cash flow, discount rate and debt and ultimately influence the shareholder value of a company. [14]

As the global container shipping lines are a logistic network and international supply chain basis, it is necessary to consider company management as the value-based Supply Chain Management. [9]

Shareholder value added is influenced by the cash flow from operations, the discount rate and the debt. The discount rate in turn is affected by the cost of capital, while cash flows from operations are driven by sales growth, profit margins and tax rates as well as by working capital and fixed assets and furthermore by value growth duration. The cost of capital is related to financing decisions, working capital and fixed assets are influenced by investment decisions, sales growth, profit margin and tax rate are stimulated by operating management decisions. [14]

The conceptual design of a framework for value-based SCM comprehended as production process, influences company value by four financial drivers: sales, cost, working capital and fixed assets.
Thus, indicators system development for global container shipping line activity assessment needs to provide control on influencing company value by above-stated factors. Besides, during company digital transformation it is necessary to control investment and financial decisions quality.

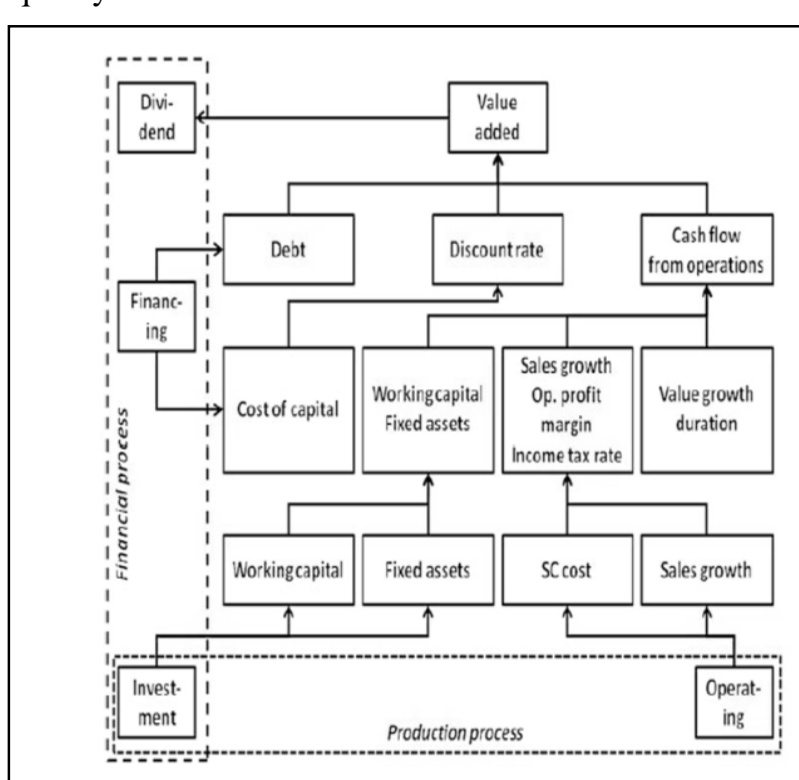

Fig. 1. Conceptual framework for value- based SCM [9]

The Balanced Scorecard, suggested in this paper, is a logical extension of value-based Supply Chain Management Framework.

The financial perspective represents a set of the operating, financial, investment activity goals, and strategic objectives of company financial position should also be defined. The digital transformation strategic objectives achievement will allow increasing the company long-term shareholder value. Strategic objectives of customer, internal process, and organizational capacity perspective are specified by decomposition of the financial perspective goals via drivers.

As already mentioned, the company long-term shareholder value.is determined by the cost of capital, the tax rate, and the company value growth duration as well as such logistic network operational process management drivers as sales growth, working capital, supply chain operational cost and assets efficiency. Thus, digital transformation strategic objectives could be defined; their achievement will allow to increase the long-term shareholder value of global container shipping line:

1) market share increasing (loyal customers);

2) new products and services sales;

3) sales to new customers;

4) value co-creation;

5) working capital effectiveness maximizing;

6) service maintenance costs reducing;

7) assets utilization effectiveness maximizing. 
Besides, the company's financial activity strategic objectives are: financial instruments profit obtaining, favorable financing terms; company investment activity strategic objective is specified: return on invested capital gaining; company financial position strategic objectives are determined: ongoing activity profit obtaining, company financial sustainability.

Financial perspective strategic indicators could be set in accordance with the DuPont Formula theory.

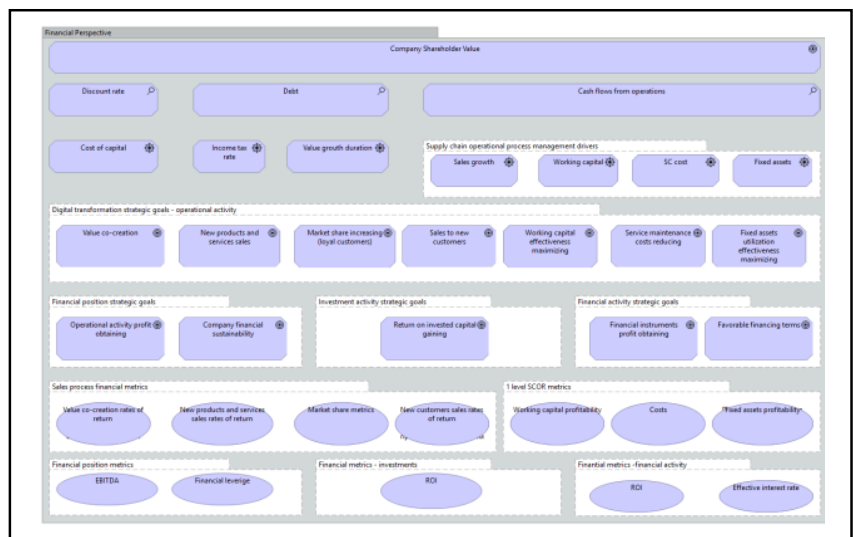

Fig. 2. Financial Perspective strategic map

In the marketing environment, there are currently a number of critical business transformations, all with significant implications for supply chain management. They could be characterized as follows: a shift of marketing strategy from the supplier to customer; from the push strategy to the pull strategy; from inventory to information; from transactions to relationships; from "trucks and warehouses" to end-to-end pipeline management; from functions to processes; from the stand-alone competition to network rivalry. [15]

Customer Perspective drivers reflect the processes happening in supply chain management and the factors influencing their changes: real demand information obtaining; customer relations management; flexibility and efficiency for customers; delivery process end-to-end integrated management; resources flexibility; focus on the processes creating value for clients; effective use of resources and competences of partners; digital marketing tools usage.

For the customer perspective strategic objectives definition, it is necessary to use a strategic model marketing mix and strategic and digital marketing tools.

The customer perspective strategic objectives are as follows:

1) timely obtaining information about actual demand;

2) partners competences and resources nobility and use;

3) lead generation;

4) customer service level increase;

5) omnichannel sales;

6) yield management;

7) enforceable contracts;

8) on time cargo delivery.

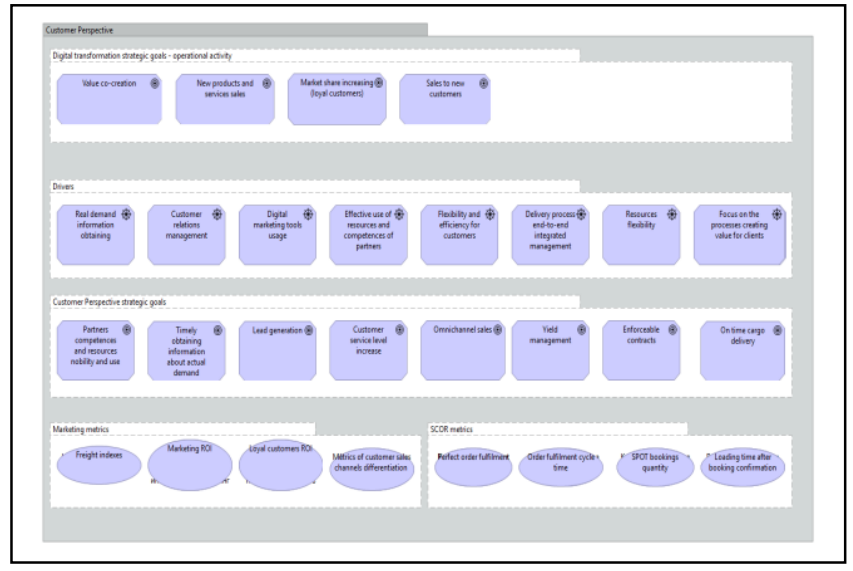

Fig. 3. Customer Perspective strategic map

The customer perspective strategic indicators could be set with the metrics, used in strategic and digital marketing.

As a basis of the internal process perspective in this paper the Supply Chain Operations Reference Model was used. This model is built around six major processes: PlanSource-Make-Deliver-Return-Enable; and covers the key supply chain activities from identifying the customer demand through to delivering the product and collecting the money. The aim of SCOR is to provide a standard way to measure the supply chain performance and to use common metrics to benchmark against other organizations. [15]

Internal process drivers in accordance with SCOR are defined as performance, processes, practices, people; strategic goals are determined as strategic characteristics of supply chain performance: reliability, responsiveness, agility, costs, and asset management efficiency.

SCOR provides an opportunity to analyze supply chain processes and to correlate internal process perspective indicators with other Balanced Scorecard indicators therefore the SCOR model become extremely an effective tool during the company's digital transformation.

SCOR does not attempt to prescribe how an organization should conduct its business or tailor its systems/information flow. Every organization that implements supply chain improvements using SCOR will need to extend the model, using industry, organization, and/or location-specific processes, systems, and practices. [16]

The global container shipping line backbone network is deployed based on the major vessels on deep-sea routes connecting hubs as well as major ports. In addition to this, it has a large range of more localized niche and feeder services. Established cargo flows as well as effective assets management have a high influence on global container shipping line processes.

The system of key performance indicators for the commercial fleet operating activity analysis and benchmarking was developed by the Baltic and International Maritime Council (BIMCO) - the international sea trade transportations industry association. This system was organized as a standard, named BIMCO Shipping KPI Standard. 
Special vessel characteristics are loading capacity, speed and consumed fuel. These technical characteristics have a considerable influence on vessel use efficiency indicators. However, vessel calls network modeling has the most significant effect on commercial fleet efficiency.

The commercial fleet utilization in the container transport is called liner ship fleet planning and consists of three main objectives:

1) optimum vessels size and fleet structure;

2) optimum fleet operation mode;

3) optimum vessel calls network.

Capacity management is an important part of supply chain management, allowing the companies to be competitive in the market and to fulfill customer requirements in the most flexible way with minimum expenses.

The container liner shipping industry possesses considerable impact on the environment due to its global activity. Compliance to environmental protection standards is an essential indicator of global container shipping line activity. Universal safety and environmental efficiency standards are defined by the International Maritime Organization - the specialized agency of the United Nations, besides, safety and environmental efficiency standards can be established by national acts.

Internal Process Perspective indicators need to be amended with BIMCO Shipping KPI Standard, IMO standard, capacity management metrics.

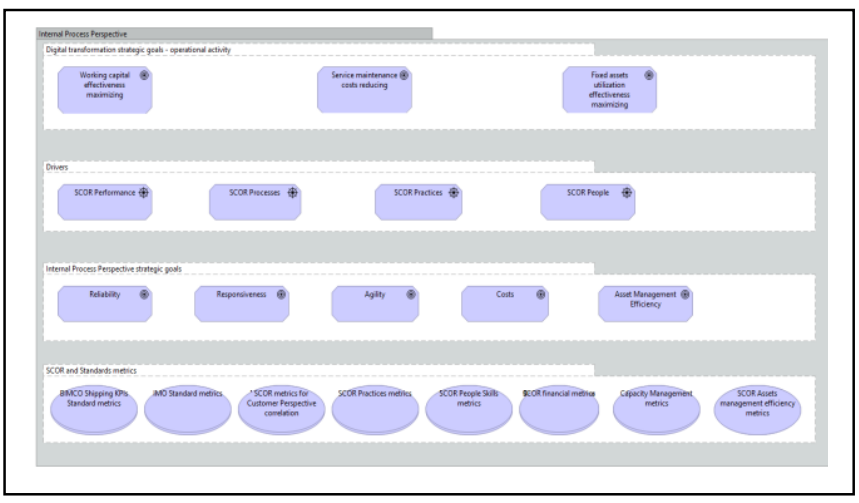

Fig. 4. Internal Process strategic map

Learning and growth perspective drivers are people, infrastructure and technology, and culture.

The SCOR model allows correlating of performance, processes, practices indicators with the supply chain personnel skills. Besides, the BIMCO Shipping KPIs Standard establishes requirements to human resource management to ensure safe and efficient operations of the ships.

During the global container shipping line digital transformation, IT-architecture strategic indicators, initiatives and problems definition and IT-architecture changes control by expert organizational structure are needed.
The Open Group Architecture Framework (TOGAF) originated as a generic framework and methodology for development of technical architectures but evolved into an enterprise architecture framework and method could be tool for enterprise architecture design. [17]

The Architecture Development Method (ADM), which is considered the TOGAF core, and consists of a stepwise cyclic approach for the development of the overall enterprise architecture, will provide necessary support for global container shipping line IT-architecture modelling. [18]

To set strategic indicators for company EA governance it is relevant to use COBIT and ITIL frameworks.

COBIT (Control Objectives for Information and related Technology) framework is the international standard, supported by global consortium ISACA, provides good practices across company domains and process framework and presents activities in a manageable and logical structure. COBIT's good practices are strongly focused on control; these practices will help to optimize IT-enabled investments, ensure service delivery and provide a measure of service fails. [19]

The business orientation of COBIT consists of linking business goals to IT goals, providing metrics and maturity models to measure their achievement, and identifying the associated responsibilities of business and IT process owners. The process structure of COBIT and its high-level, business-oriented approach provide an end-to-end view of IT and the decisions to be made about IT. [19]

COBIT framework defines data as an initial resource and sets the following criteria to which they have to comply: effectiveness, efficiency, confidentiality, integrity, availability, compliance, reliability. Other IT resources and IT processes should be aligned in order to provide data compliance to the above-stated criteria and company business goals performance. [19]

IT Infrastructure Library (ITIL) framework is a source of good practice and is used to establish and improve capabilities in service management. While ISO/IEC 20000 is a standard to be achieved and maintained, ITIL offers a body of knowledge useful for achieving the standard.

The ITIL describes the principles of IT services continuous improvement and existing frameworks, standards and quality management models: PMBOK, PRINCE2, CMMI, ISO/IEC 20000, ISO/IEC 27001, ISO/IEC 17799 and others. The ITIL recommends using them in the combination, the most suitable for the specific company. [20]

Learning and growth perspective strategic goals of global container shipping lines have to provide company digital transformation strategic objectives achievement and could be formulated as follows:

1) data compliance to specified criteria;

2) IT resources effectiveness;

3) IT processes effectiveness; 
4) data architecture compliance to company strategic goals;

5) business and IT application architecture alignment

6) business and infrastructure architecture alignment;

7) IT projects effectiveness;

8) personnel high qualification.

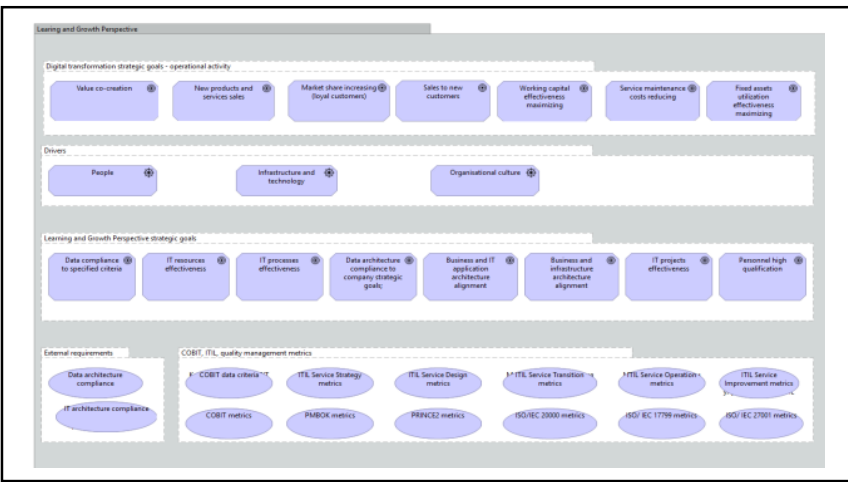

Fig. 5. Learning and Growth Perspective strategic map

Learning and growth perspective strategic indicators have to provide data architecture and IT architecture compliance both legislation requirements as well as requirements of the standards and frameworks.

\section{DISCUSSION}

In this research paper global container shipping lines digital transformation in the context of its influence on the long-term shareholder value of the company is considered, company digital transformation strategic objectives and strategic metrics are defined for financial perspective, customer perspective, internal process perspective, learning and growth perspective. However, in this research paper digital transformation risks are not considered as this is a subject for separate research.

\section{CONCLUSION}

Global container shipping lines digital transformation will have a significant effect on all nine blocks of the company business model, will allow to create new customer offers, to cut costs, to optimize company assets utilization, to create new sales and key partners interaction channels, to reduce negative factors influence and to create further successful company development concept.

Nevertheless, it is necessary to formulate the following requirements to company digital transformation:

1) Digital transformation has to comply with company strategic objectives.

2) Digital transformation demands cross-disciplinary approach.

3) Digital transformation is impossible without approach change to collecting, transfer, storage, processing, and the analysis of data.

4) Digital transformation has to be based on the international standards, industry standards; international consortiums and organizations reference models and frameworks.
5) Digital transformation demands continuous approach, with constant results assessment and actions correction.

To meet these requirements ESAM method application and the Balanced Scorecard, developed in this research paper, is appropriate for global container shipping line digital transformation.

\section{REFERENCES}

[1] Maydanova, S and Ilyin, I. (2018), Analysis of the linear container shipping industry current state and prospects of its further development, Lodistics and Supply Chain Management, no. (84), pp. $40-58$

[2] Jensen, L. (2017), Liner Shipping in 2025. How to survive and thrive, 1st edition, Vespucci Maritime Publishing ApS.

[3] The Digital Imperative in Container Shipping (2018), The Boston Consulting Group. available at https://www.bcg.com/ruru/publications/2018/digital-imperative-container-shipping.aspx (Accessed 09 March 2018).

[4] Baker, J. and Jones, D. (2008). A theoretical framework for sustained strategic alignment and an agenda for research. In Proceedings of JAIS Theory Development Workshop (vol.8, pp. 1-30)

[5] Aldea, A.I. (2017). Enterprise strategic alignment method. A crossdisciplinary capability-driven approach, Abstract of $\mathrm{PhD}$ dissertation, University of Twente, Twente, Netherlands.

[6] Osterwalder, A. (2010). Business Model Generation. New Jersey, USA.

[7] Sandkuhl, K. and Stirna, J. (2018) Capability Management in Digital Enterprises. Springer-Verlag, Berlin.

[8] Ulrich, W. and Rosen, M. (2011) The business capability map: building a foundation for business/ IT alignment. Cutter Consortium for Business and Enterprise Architecture. [Online], [retrieved February 28, 2016], http://www.cutter.com/content-andanalysis/resource -centers/ enterprise-architecture/sample-ourresearch/ea110504.html

[9] Brandenburg, M. (2013) Quantitative Models for Value-Based Supply Chain Management. Springer- Verlag, Berlin.

[10] Kaplan, R.S. and Norton, D.P., (2004), Strategy Maps: converting intangible assets into tangible outcomes, Harvard Business School Press, USA

[11] Gomez- Uranga, M. et all (2016). Dynamics of Big Internet Industry Groups and Future Trends. Springer, Switzerland.

[12] Aldea, A. et all (2018). Enterprise Architecture 4.0 - A vision, an approach and software tool support. IEEE 22nd International Enterprise Distributed Object Computing Conference.

[13] Modigliani, F., and M. Miller, (1958). The cost of capital, corporation finance and the theory of investment. American Economic Review 48: 261-197.

[14] Rappaport, A. (1998). Creating shareholder value. New York: The Free Press.

[15] Christopher, M. (2005). Logistics and Supply Chain Management. Creating value- added networks. Pearson Education Limited, Great Britain.

[16] APICS. Supply Chain Operations Reference Model SCOR. Version 12.0. (2017). APICS, Chicago, USA

[17] Ilin, I., Levina, A., Abran, A., Iliashenko, O. (2017) Measurement of Enterprise Architecture (EA) from an IT perspective: Research gaps and measurement avenues. ACM International Conference Proceeding SeriesPart F131936, 2017. Pp. 232-243

[18] Lankhorst, M. et al. (2017) Enterprise Architecture at Work. Modelling, Communication and Analysis. Springer- Verlag, Berlin.

[19] A Business Framework for the Governance and Management of Enterprise IT. COBIT an ISACA framework. (2012). ISACA, USA.

[20] The Official Introduction to the ITIL Service Lifecycle. (2007). TSO, United Kingdom. 